\title{
Haematological responses of the Indian major carp Labeo rohita to saprolegniasis
}

\author{
CHANDAN DEBNATH*, BASANTA KUMAR DAS ${ }^{* *}$ AND LOPAMUDRA SAHOO* \\ ICAR-Central Institute of Freshwater Aquaculture, Bhubaneswar - 751 002, Odisha, India \\ *ICAR-Research Complex for North-Eastern Hill Region, Tripura Centre, Lembucherra - 799 210, West Tripura, India \\ ${ }^{* *}$ ICAR-Central Inland Fisheries Research Institute, Barrackpore - 700 120, West Bengal, India \\ e-mail: chandannath23@gmail.com
}

\begin{abstract}
Saprolegniasis (cotton wool disease), due to infestation by Saprolegnia parasitica, is a major fungal disease in fish. Present study was conducted in the Indian major carps, rohu, Labeo rohita (Hamilton, 1822). Fingerlings of rohu (10.5 $2.2 \mathrm{~g}$ ) were artificially infected with the fungal parasite $S$. parasitica via injection (T1), cohabitation (T2) as well as immersion (T3) and compared with a control group (T0) with no infection. Blood samples were collected at 15 days interval over a period of 45 days and analysed for haematological parameters. Haemoglobin level in infected fish was lower $(p \leq 0.05)$ than non-infected fish on 15,30 and 45 days post-infection (dpi) except in cohabited fish on 45 dpi. Total erythrocyte count (TEC) in infected fish was lower $(\mathrm{p} \leq 0.05)$ than non-infected fish on 15,30 and 45 dpi. Total leucocyte count (TLC) was higher $(\mathrm{p} \leq 0.05)$ in infected fish on $15 \mathrm{dpi}$; however no difference $(\mathrm{p} \geq 0.05)$ was noticed on 30 dpi. TLC in injected group was higher $(\mathrm{p} \leq 0.05)$ than control group on 45 dpi. Haematocrit $(\mathrm{Hct})$, mean corpuscular volume (MCV), mean corpuscular haemoglobin $(\mathrm{MCH})$, mean corpuscular haemoglobin concentration $(\mathrm{MCHC})$ and leucocrit (Lct) values in infected group were lower $(p \leq 0.05)$ than control group. There was no difference $(p \geq 0.05)$ in mortality among the groups on 15 dpi; however, on 30 and $45 \mathrm{dpi}$, the group subjected to immersion exposure recorded highest mortality followed by injected and cohabitated groups. Varying degrees of histological alterations were observed in the tissues due to the fungal infestation. The results indicated that $S$. parasitica significantly altererd the blood profile of infected rohu leading to $45-50 \%$ mortality. Therefore appropriate management measures need to be adopted for preventing infestation by $S$. parasitica in carp culture systems for realising sustainable fish production.
\end{abstract}

Keywords: Artificial infection, Haematology, Labeo rohita, Saprolegnia parasitica

\section{Introduction}

Saprolegniasis is a major setback in fisheries and aquaculture (Willoughby, 1994). It is the second most important fungal disease in fish after epizootic ulceration. The causative agent of this disease is a water mold, known as Saprolegnia parasitica. The disease is also called 'cotton wool disease' due to the appearance of cotton-like white to greyish patches, radiating in circular, crescent or whorl pattern on skin and gills of affected fish. The infection spreads faster once hyphae invades epidermal tissue. All life stages of fish such as spawn, fry and fingerlings suffer due to saprolegniasis. The pathogen is transmitted through infected fish, eggs, water and equipment (Brunoand Wood, 1999). Malachite green is the most effective chemotherapeutant against the fungus; however, its use is banned since 2002 due to toxicological effects. As a result, there is a dramatic re-emergence of the disease in commercial farms. At present, formalin and Pyceze (a pesticide) are recommended against this disease; however, they are also expected to be prohibited in near future because of environmental issues (van West, 2006). Therefore, alternative strategies are urgently needed to control saprolegniasis in fish culture systems. Understanding the mode of action of Saprolegnia through artificial infection will be helpful for developing strategies to control infections (Howe and Stehly, 1998). Blood parameters were used earlier as an indicator of fish physiology during mycosis (Wedemeyer, 1970); however, so far no study has been conducted in Indian major carps. Therefore, the present study was attempted in rohu Labeo rohita (Hamilton, 1822) which is a major aqua-crop species in India, to study the sequential changes during infection by $S$. parasitica.

\section{Materials and methods}

The study was conducted at the Fish Health Management Division of the ICAR-Central Institute of Freshwater Aquaculture (ICAR-CIFA), Bhubaneswar, Odisha. Fingerlings of rohu $(10.5 \pm 2.2 \mathrm{~g})$, procured from 
ICAR-CIFA farm were used for the experiments. The fish were transported in 5001 capacity tanks with air pump. They were carefully transferred to circular tanks (1000 1) and left undisturbed overnight. To ameliorate handling stress, fish were dipped in a mild salt solution $(3 \% \mathrm{NaCl})$ on the next day and acclimatised under aerated condition over a period of 15 days before commencement of the challenge experiment. Fish were observed for overall health, behaviour and presence of any diseases. Crowding and handling were kept minimal and pellet feed having $20 \%$ crude protein was provided at $3 \%$ of body weight, twice daily. Aeration was regularly provided and water quality was maintained at normal levels. Water parameters, estimated following standard methods (APHA, 1998) were: dissolved oxygen $7.6 \pm 0.2 \mathrm{ppm}$, temperature $27 \pm 1^{\circ} \mathrm{C}$, $\mathrm{pH} 7.4 \pm 0.2$, total alkalinity $230 \pm 10 \mathrm{ppm}$, hardness $40 \mathrm{ppm}$, carbon dioxide $2.5 \mathrm{ppm}$, chloride $40 \mathrm{ppm}$, ammonia 0.27 ppm, nitrate $0.02 \mathrm{ppm}$, nitrite $0.05 \mathrm{ppm}$ and phosphate $0.003 \mathrm{ppm}$. Fish showing active movement and good health, were used for challenge experiment with one of the strains of the fungus $S$. parasitica isolated and identified at ICAR-CIFA. Sporulation was induced in the fungus as per Dieguez-Uribeondo et al. (2007) and spore density was adjusted to $2.5 \times 10^{4} \mathrm{ml}^{-1}$.

The fish were infected with the fungal spores via injection (T1), cohabitation (T2) and immersion (T3). In control group (T0), 30 fish were kept with no spore inoculation. The injected and cohabited groups comprised 40 fish, of which 20 were intramuscularly injected with spore at $0.2 \mathrm{ml}$ per fish and remaining 20 were allowed to co-habit in the same tank with injected fish after amputating one of the caudal fin lobe to mark they are non-injected. In the group exposed to immersion challenge, 40 fish were kept and spores inoculated at $1 \mathrm{ml}$ per liter of water. Triplicate tanks were maintained for each group. Relative percent survival and behaviour of the challenged fish were monitored regularly. At 15, 30 and 45 days post-infection (dpi), six fish were randomly sampled from each group and bled through cardiac vein for analysis of haematological parameters. During each sampling, one fish from each group was dissected and tissue samples collected for histological study and re-isolation of fungus (Chauhan et al., 2014). Moribund specimens were analysed for the presence of fungus and fishes from which fungus was reisolated, were considered affected by saprolegniasis. The experiment lasted for 45 days.

The blood samples were analysed for haemoglobin $(\mathrm{Hb})$ by cyanmethaemoglobin method (Van Kampen and Zijlstra, 1961). Total leucocytes count (TLC) and total erythrocytes count (TEC) were estimated using haemocytometer (Russia and Sood, 1992). Haematocrit
(Hct), mean corpuscular volume (MCV), mean corpuscular haemoglobin $(\mathrm{MCH})$, mean corpuscular haemoglobin concentration (MCHC) and leucocrit (Lct) were analysed as per Shah (2010). Relative percentage survival (RPS) of fish in different groups was determined at 15 days interval. The data were analysed using one-way analysis of variance (ANOVA) in SPSS 21 to find out difference at $5 \%$ level of significance.

For histological examination, tissues were fixed in $10 \%$ neutral buffered formalin for $48 \mathrm{~h}$ and processed routinely for the preparation of paraffin blocks as per the methods of Chauhan et al. (2014). The paraffin blocks were then sectioned at $5 \mu \mathrm{m}$ thickness, stained with haematoxylin and eosin (H\&E) and the slides were observed under microscope to see for any change in tissue architecture.

\section{Results and discussion}

Results of the haematological investigations in fish due to Saprolgeniasis are presented in Table 1 and Fig. 1. The haemoglobin content was decreased significantly $(\mathrm{p} \leq 0.05)$ in infected fish compared with non-infected fish. On 15 dpi, haemoglobin level in injected group (T1) was lower $(\mathrm{p} \leq 0.05)$ than groups challenged by cohabitation (T2) and immersion (T3). However no difference ( $\mathrm{p} \geq 0.05)$ was observed between fishes in T2 and T3 groups. On 30 dpi, haemoglobin in group T1 was lower $(\mathrm{p} \leq 0.05)$ than fishes in groups T2 and T3 and on $45 \mathrm{dpi}$, haemoglobin content in group $\mathrm{T} 1$ and $\mathrm{T} 2$ was lower $(\mathrm{p} \leq 0.05)$ than T2. The same was confirmed through blood smearing. This down fall could be attributed to impairment in erythropoiesis and haemoglobin synthesis in fish. Gardner (1974) as well as Hatai and Hoshiai (1994) observed similar condition in salmons dying due to saprolegniasis.

Table 1. Effect of Saprolegnia parasitica infection on selected blood parameters ( $\mathrm{Hb}, \mathrm{TLC}$ and TEC) of $L$. rohita

\begin{tabular}{lllll}
\hline Parameters & Groups & $15 \mathrm{dpi}$ & $30 \mathrm{dpi}$ & $45 \mathrm{dpi}$ \\
\hline Haemoglobin $(\mathrm{g} \%)$ & T0 & $4.47 \pm 0.07^{\mathrm{a}}$ & $4.27 \pm 0.07^{\mathrm{a}}$ & $4.00 \pm 0.12^{\mathrm{a}}$ \\
& T1 & $3.20 \pm 0.12^{\mathrm{c}}$ & $2.73 \pm 0.07^{\mathrm{d}}$ & $2.27 \pm 0.07^{\mathrm{b}}$ \\
& T2 & $3.73 \pm 0.07^{\mathrm{b}}$ & $3.93 \pm 0.07^{\mathrm{b}}$ & $3.87 \pm 0.07^{\mathrm{a}}$ \\
& T3 & $3.80 \pm 0.12^{\mathrm{b}}$ & $3.20 \pm 0.12^{\mathrm{c}}$ & $2.33 \pm 0.07^{\mathrm{b}}$ \\
\hline TEC $\left(\times 10^{6} \mathrm{~mm}^{-3}\right)$ & T0 & $0.68 \pm 0.04^{\mathrm{a}}$ & $0.85 \pm 0.06^{\mathrm{a}}$ & $0.91 \pm 0.02^{\mathrm{a}}$ \\
& T1 & $0.36 \pm 0.04^{\mathrm{b}}$ & $0.28 \pm 0.03^{\mathrm{c}}$ & $0.18 \pm 0.02^{\mathrm{b}}$ \\
& T2 & $0.23 \pm 0.03^{\mathrm{b}}$ & $0.12 \pm 0.03^{\mathrm{c}}$ & $0.20 \pm 0.003^{\mathrm{b}}$ \\
& T3 & $0.28 \pm 0.07^{\mathrm{b}}$ & $0.45 \pm 0.07^{\mathrm{b}}$ & $0.13 \pm 0.006^{\mathrm{c}}$ \\
\hline TLC $\left(\mathrm{x} 10^{3} \mathrm{~mm}^{-3}\right)$ & T0 & $2.5 \pm 0.06^{\mathrm{c}}$ & $26.00 \pm 5.77^{\mathrm{a}}$ & $7.7 \pm 1.74^{\mathrm{bc}}$ \\
& T1 & $12.0 \pm 0.58^{\mathrm{a}}$ & $30.33 \pm 2.03^{\mathrm{a}}$ & $27.33 \pm 2.33^{\mathrm{a}}$ \\
& T2 & $9.33 \pm 0.38^{\mathrm{b}}$ & $19.67 \pm 4.18^{\mathrm{a}}$ & $4.7 \pm 1.04^{\mathrm{c}}$ \\
& T3 & $8.97 \pm 0.15^{\mathrm{b}}$ & $29.67 \pm 4.80^{\mathrm{a}}$ & $11.6 \pm 2.09^{\mathrm{b}}$ \\
\hline
\end{tabular}

Mean values bearing different superscripts within a column for a parameter are significantly different $(\mathrm{p} \leq 0.05)$ 


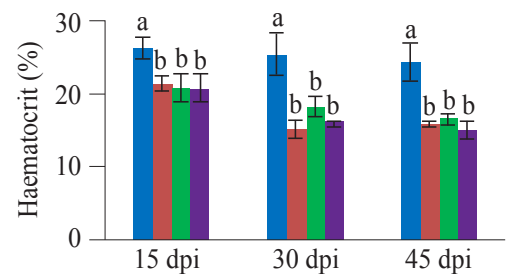

(a)

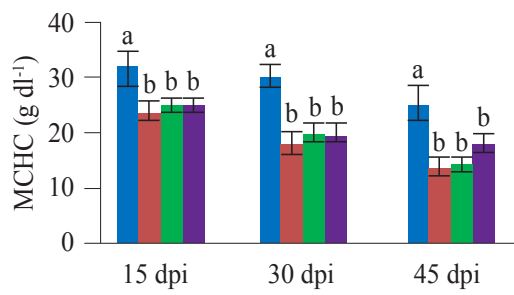

(d)

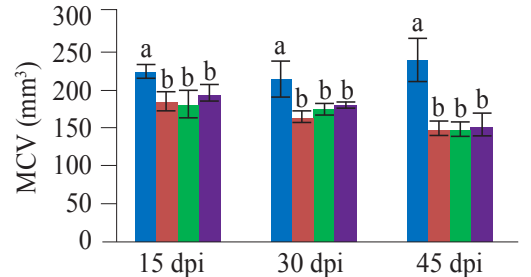

(b)

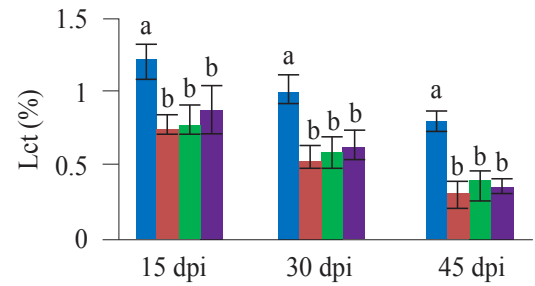

(e)

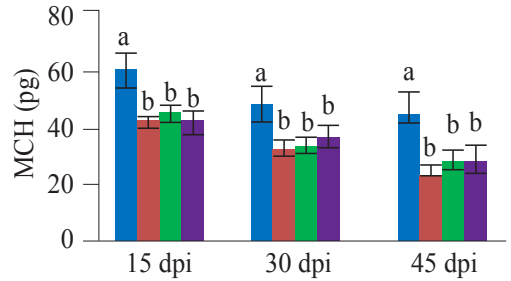

(c)

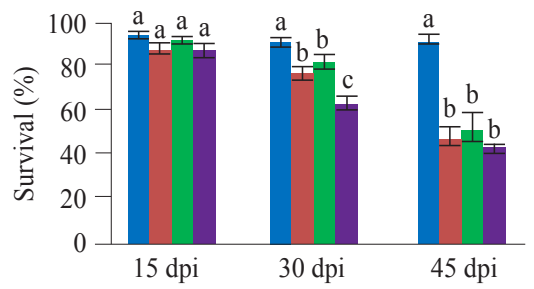

(f)

- Control (T0), Injection (T1), — Cohabitation (T2), a Immersion (T3)

Fig. 1. Haematocrit (a), MCV (b), MCH (c), MCHC (d) Lct (e) values and (f) survival rate in Labeo rohita fingerlings exposed to Saprolegnia parasitica via different challenge routes

TEC in all the three groups on 15 dpi was lower $(\mathrm{p} \leq 0.05)$ than control group (T0); however, no difference $(\mathrm{p} \geq 0.05)$ was noticed among the infected groups. On 30 dpi, TEC in groups T1 and T2 was lower $(\mathrm{p} \leq 0.05)$ than that of fishes in group T3; however, no difference $(\mathrm{p} \geq 0.05)$ was observed between groups $\mathrm{T} 1$ and $\mathrm{T} 3$. On $45 \mathrm{dpi}$, the TEC was found decreased $(\mathrm{p} \leq 0.05)$ in group $\mathrm{T} 1$ as compared with T2 and T3; however, no difference $(\mathrm{p} \geq 0.05)$ was found between $\mathrm{T} 1$ and $\mathrm{T} 2$. This was a strong indicator of stress in fish (McLeay and Gordon, 1977). Destruction of haematopoietic tissue in kidney and spleen would have led to such decrease in blood cell production and subsequent reduction in their count. Similar results have been reported in tench by Shah (2010).

TLC in infected fish on 15 dpi was higher $(\mathrm{p} \leq 0.05)$ than control fish. In group $\mathrm{T} 1$, it was higher $(\mathrm{p} \leq 0.05)$ than groups $\mathrm{T} 2$ and $\mathrm{T} 3$. However, no significant difference $(\mathrm{p} \geq 0.05)$ was observed between $\mathrm{T} 2$ and $\mathrm{T} 3$ groups. On $30 \mathrm{dpi}$, no difference $(\mathrm{p} \geq 0.05)$ was noticed in the three treatment groups. In group T1, on $45 \mathrm{dpi}$, TLC was higher $(\mathrm{p} \leq 0.05)$ than control group. In $\mathrm{T} 3$, it was higher $(\mathrm{p} \leq 0.05)$ than $\mathrm{T} 2$, but no significant difference $(\mathrm{p} \geq 0.05)$ was found in T2 and T3 compared with control group. Increase in levels of TLC could be due to increase in production of lymphocytes, thrombocytes and lymphocytosis or squeezing of leucocytes into peripheral blood (Das and Mukherjee, 2000) and decreased levels of TLC could be attributed to increase in secretion of corticosteroids following stress (Tort et al., 1987).

Hct, Lct, MCV, MCH and MCHC in all the three treatment groups were lower than $(\mathrm{p} \leq 0.05)$ control group throughout the study period. The rate of fall in the levels of these parameters was drastic with the progress of time; however, no difference ( $\mathrm{p} \geq 0.05$ ) was noticed among them over a period of 45 days. Involvement of non-leucocyte cells in the defence against fungus might be the cause of such drop in Hct, $\mathrm{Hb}$ and $\mathrm{RBC}$ in infected groups of fish (Shah, 2010).

Saprolegnia infection caused significant fish mortality (Fig. 1f) in all the challenged groups. There was no difference $(p \geq 0.05)$ in survival of fish among injected, cohabitated and immersed groups compared with control group on 15 dpi. On $30 \mathrm{dpi}$, survival was reduced $(\mathrm{p} \leq 0.05)$ in infected groups compared with control fish. In group T3, survival was lower $(p \leq 0.05)$ than $\mathrm{T} 1$ and $\mathrm{T} 2$ groups; however, no difference $(\mathrm{p} \geq 0.05)$ was noticed between groups T1 and T2. On 45 dpi, survival in infected groups fell significantly $(\mathrm{p} \leq 0.05)$ compared with non-infected control fish; however, no significant difference $(p \geq 0.05)$ was observed among the infected groups. Hightest mortality (45\%) was recorded in group T3 challenged by immersion exposure which could be attributed to ingestion of infective spores which might have multiplied faster in the tanks under congenial water conditions. The injury due to caudal fin amputation was responsible for infection and fish mortality in cohabitated group (Bruno and Wood, 1999).

Deep penetration of hyphae in the muscle (Fig. 2) and gill tissues, would have caused haemodilution and breakdown of osmoregulation and as a result fish suffered mortality. Shah and Altindag, (2004) observed erythrocyte fragility and haemorrhage leading to anaemia in fish. Damage of haematopoietic tissue and haemodilution 


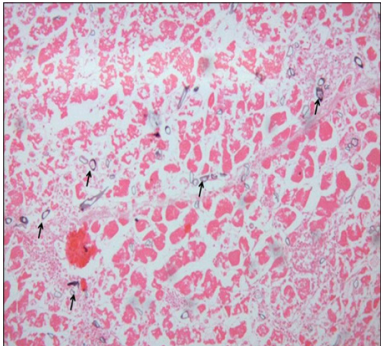

(a)

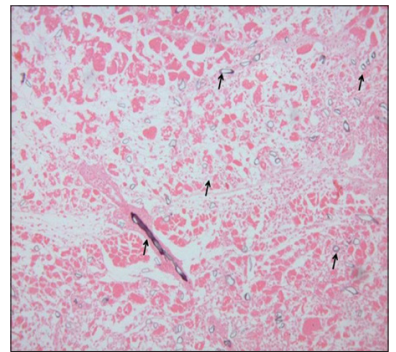

(b)
Fig. 2. Histological sectionsg showing deep penetration of fungal hyphae into the muscle tissue of infected fish $($ Scale bar $=100 \mu \mathrm{m})$

hampered erythrocyte production (Wepener et al., 1992), whereas, alteration in membrane permeability and mechanical fragility (Gill and Epple, 1993) and haemolysis (Tort et al., 1987) accelerated erythroclasis. The infected fish showed symptoms of lethargy which could be attributed to excessive energy exerted to overcome stress and there was excess mucus secretion in gills which caused increase in the diffusion distance between water and haemoglobin. As a result, gas exchange in the body was found to be rapidly hampered and fish became exhausted. Impairment in gas exchange might have triggered erythropoiesis to maintain haemoglobin at normal level; however, continuous exposure to fungus has suppressed this capacity leading to decreased levels of TEC. In this study, fungal infection was confirmed histologically at tissue level by presence of fungal hyphae in tissue sections and also samples from challenged groups were found positive for S. parasitica during re-isolation of the fungus on PDA. Loss of epidermis, necrotised hypodermis with hyphal growth and destroyed musculature were observed at tissue level (Fig. 2) similar to the condition reported by Chauhan et al. (2014).

Results of the study clearly indicated that, rohu suffered haematological aberrations during $S$. parasitica infection leading to $45-55 \%$ mortality in infected fish. However, this is a preliminary attempt on examination of physiological impairment in a stock of Indian major carp due to saprolegniasis under controlled conditions. Further investigations are needed at population level with other strains of the fungus.

\section{Acknowledgements}

We are thankful to Dr. N. Sarangi, Former Director of ICAR-CIFA, Bhubaneswar for providing all the necessary facilities to conduct this study. The fellowship provided by ICAR-CIFE, Mumbai to carry out the research work is also gratefully acknowledged.

\section{References}

APHA 1998. Standard methods for examination of water and waste water, $20^{\text {th }}$ edn. American Public Health Association, Washington, DC, USA, 1220 pp.

Bruno, D. W. and Wood, B. P. 1999. Saprolegnia and other Oomycetes. In: Woo, P. T. K. and Bruno, D. W. (Eds.), Fish diseases and disorders, vol. III, viral, bacterial and fungal infections. Wallingford, Owon, CABI Publishing, UK, p. 599-659.

Chauhan, R., Faroq, A., Lone, S. A. and Ganaie, S. A. 2014. Hematological and histological investigations on healthy and Saprolegnia sp. infected Clarias gariepinus (Burchell, 1822). Int. J. Experiment. Pharmacol., 4(2): 97-100.

Das, B. K. and Mukherjee, S. C. 2000. Chronic toxicity effect of quinalphos on some biochemical parameters in L. rohita (Ham). Aquaculture, 144: 11-18

Dieguez-Uribeondo, J., Fregeneda-Grandes, J. M., Cerenius, L., Perez-Iniesta, E., Aller-Gancedo, J. M., Telleria, M. T., Soderhall, K. and Martin, M. P. 2007. Re-evaluation of the enigmatic species complex Saprolegnia diclina-Saprolegnia parasitica based on morphological, physiological and molecular data. Fungal Gen. Biol., 44: 585-601.

Gardner, M. L. G. 1974. Impaired osmoregulation in infected salmon, Salmo solar L. J. Mar. Biol. Ass., UK, 54: 635-639.

Gill, T. S. and Epple, A. 1993. Stress-related changes in the haematological profile of the American eel (Anguilla rostrata). Ecotoxicol. Environ. Safety, 25: 227-235.

Hatai, K. and Hoshiai, G. I. 1994. Pathogenicity of Saprolegnia parasitica Coker. In: Mueller, G. J. (Ed.), Salmon and saprolegniasis. U. S. Department of Energy, Bonneville Power Administration, Portland, Oregon, p. 87-98.

Howe, G. E. and Stehly, G. R. 1998. Experimental infection of rainbow trout with Saprolegnia parasitica. J. Aquatic Anim. Health, 10: 397-404.

Russia, U. and Sood, S. K. 1992. Routine haematological tests. In: Kanai, Mukherjee, L. (Ed.), Medical laboratory technology, Tata McGrow Hill Publishing Company Limited, New Delhi, p. 252-258.

Shah, S. L. and Altindag, A. 2004. Haematological parameters of tench, (Tinca tinca L.) after acute and chronic exposure to lethal and sub-lethal mercury treatments. Bull. Environ. Cont. Toxicol., 73: 911-918.

Shah, S. L. 2010. Impairment in the haematological parameters of tench (Tinca tinca) infected by Saprolegnia spp. Turkish J. Vet. Anim. Sci., 34: 313-318.

Mcleay, D. J. and Gordon, M. P. 1977. Leucocrit: A simple haematological techniques for measuring acute stresses in salmonoid fish, including stressful concentrations of pulp mill effluent. J. Fish. Res. Bd. Can., 34: 2164-2175. 
Tort, L., Torres, P. and Flos, R. 1987. Effects on dogfish haematology and liver composition after acute copper exposure. Comp. Biochem. Physiol., C 87: 349-353.

Van Kampen, E. G. and Zijlstra, W. G. 1961. Standardisation of hemoglobinometry, II. The haemoglobin cyanide method. Clinica Chimica Acta, 6: 538.

van West, P. 2006. Saprolegnia parasitica, an oomycete pathogen with a fishy appetite: new challenges for an old problem. Mycologist, 20: 99-104.
Wedemeyer, G. 1970. The role of stress in the disease of fishes. In: Sniesko, S. F. (Ed.), Proceedings of the Symposium on diseases of fishes and shell fishes, American Fisheries Society Speculation Publication, 5: 30-35.

Wepener, V., Van Vuren, J. H. J. and Du Preez. H. H. 1992. Effect of manganese and iron at a neutral and acidic $\mathrm{pH}$ on the haematology of the banded tilapia (Tilapia sparrmanii). Bull. Environ. Cont. Toxicol., 49: 613-619.

Willoughby, L. G.1994. Fungi and fish diseases. Pisces Press, Stirling, Scotland, $57 \mathrm{pp}$. 